\title{
The determinants of shopping duration on workdays in The Netherlands
}

\author{
Tim Schwanen * \\ Urban and Regional research centre Utrecht (URU), Faculty of Geographical Sciences, Utrecht University, P.O. Box 80.115, \\ 3508 TC Utrecht, The Netherlands
}

\begin{abstract}
While many studies of the duration of shopping episodes have considered the impact of sociodemographic variables, such as gender or income, few if any have considered spatial variation in the duration of shopping activities. This paper reports a study seeking to establish how the duration of shopping episodes varies with characteristics of the built environment in addition to other factors that are claimed to influence the duration of shopping episodes-temporal constraints, the monetary budget available and the activity/travel context of the shopping activity. The data used are derived from working male and female heads of household included in the 1998 Netherlands National Travel Survey. The results indicate that shopping duration on workdays is affected by temporal constraints, the activity/travel episodes conducted before or after the shopping activity, and the urban setting in which they are executed. Shopping episodes on workdays tend to take more time as the degree of urbanization of the urban setting is higher; the magnitude of this effect varies, however, with the time of day and gender.
\end{abstract}

(C) 2003 Elsevier Ltd. All rights reserved.

\section{Introduction}

Since the publication of the Brundtland and report (WCED, 1987), the number of academic publications about the impact of urban form on individuals' travel behavior has increased rapidly. Most of this literature concentrates on distance traveled and mode choice, because these travel indicators are most directly related to energy use for transportation. Other dimensions of activity/travel behavior, such as the duration of specific activities, have remained underexposed (Levinson, 1999; Schwanen et al., 2002). This is remarkable given the fact that people's travel behavior is derived from their participation in activities that are separated in space in time (Axhausen and Gärling, 1992). It can thus be argued that, for a deeper understanding of the relationship between travel patterns and urban form, the activities pursued at travel destinations should be considered in addition to the travel behavior itself.

The current paper seeks to analyze the impact of urban form on one dimension of activity behavior - the duration of shopping activity episodes. An activity epi-

\footnotetext{
* Tel.: +31-30-253-44-37/13-99; fax: +31-30-254-06-04

E-mail address: t.schwanen@geog.uu.nl (T. Schwanen).
}

sode is here defined as the period of time that an individual has spent on a single destination; the travel to/ from the destination in question is excluded. The study of the association between urban form and shopping episode duration is embedded in a theoretical framework that is drawn from the paradigm of activity-based travel-demand analysis, or activity analysis in short. Thus, in addition to characteristics of the built environment, the impact on shopping duration of a variety of other determinants is considered. The central question thus becomes: to what extent do temporal constraints, monetary budget constraints, the activity/travel context surrounding a shopping episode, and the urban setting where the episode takes place affect its duration?

Another insight emerging from the activity-analysis paradigm is that workday activity patterns are fundamentally different from those on non-workdays. On workdays, as the name implies, maintenance activities, such as shopping, as well as leisure activities have to be scheduled around work activities. Although time pressure has risen in general over the past decades (Breedveld and Van den Broek, 2001), it is during workdays that the largest number of individuals face difficulties in the scheduling of activities. Gaining insights into the determinants of non-work activities and related travel 
on these days is particularly pertinent, so that land-use/ transportation policies can be formulated that provide time-pressured individuals with easy access to the retail facilities and hence ease time constraints and scheduling problems. For these reasons, the analysis is restricted to shopping episodes on workdays.

Using data from the 1998 Netherlands National Travel Survey, coefficients of Cox regression models are estimated to analyze the effects of the sets of factors identified above on shopping duration during workdays in The Netherlands. Separate models are estimated for male and female heads of households and for five different parts of the workday. In contrast with many previous studies of shopping episode duration (Bhat, 1996, 2001, for instance), the analysis covers all parts of the workday and recognizes that women's shopping behavior may be driven by other factors than men's shopping episodes on workdays.

\section{Literature review and hypotheses}

A survey of the relevant literature shows that many different factors have been related to the duration of shopping episodes. In this study these explanatory factors are classified into four groups: temporal constraints, the activity/travel episodes surrounding shopping episodes in an activity pattern; monetary budget constraints; and the spatial environment where the shopping is conducted. Because the last group of factors has received only limited attention, the potential role of the spatial environment is discussed in detail.

\subsection{Temporal constraints}

Temporal constraints result from the approximate start time and duration of certain activities being fixed for one or more household members. The duration of fixed activities, such as work or household and personal care, limit the amount of time available for other, more flexible activities. This amount of time has been referred to in the literature as a time window or time budget (Schwanen and Dijst, 2003).

Several studies have indicated that, as people spend more time on the fixed activity of out-of-home work, they allocate less time to shopping episodes (Bhat, 2001; Kasturirangan et al., 2002). Further, the amount of time a person allocates to work has implications for the spouse's time use. Bhat (1996) found evidence of crossperson effects of work duration on the length of shopping episodes. As men work longer, women spend more time shopping during the return-home commute. The effect of the male spouses' work duration was even stronger than that of their own work time. The opposite situation (men's episode duration being affected by their wives' work duration) also occurred, but to a much smaller extent.

Apart from the time allocated to working, the extent to which individuals have to take care of other persons in the household may limit the duration of time windows. Using data from the Puget Sound Area, Niemeier and Morita (1996) showed that shopping activities tended to be shorter when the number of children aged 6 17 years was greater. A follow-up study indicated that, while this holds true for women, the opposite was the case for men: as the number of children increased, the duration of men's visits to shops was also longer (Yee and Niemeier, 2000). Over time (1989-93) this genderrelated difference narrowed, however.

Temporal constraints also come into play when, given a certain amount of time available for more flexible activities, the number of activities a person needs or wants to perform increases. In other words, the number of activities within a time window must be traded off against the time per activity, which may result in a shorter duration per episode (Kitamura et al., 1981).

Finally, temporal constraints on shopping duration may not only result from coupling constraints or interactional limitations but also from authority constraints resulting from rules and laws (Hägerstrand, 1970). Store hours limit the opportunities to participate in shopping during certain parts of the day or week. Only partial evidence is available about the effect of store hours on shopping duration. Breedveld and Van den Broek (2001) have investigated changes in households' shopping behavior after the extension of store hours in The Netherlands in 1996. The total time spent shopping did not vary statistically significantly before and after the extension. However, there is some evidence for a shift of shopping episodes from conventional hours to Sundays and evening hours, especially for 'new' household types (working singles, two-earner couples and families, and so forth). Using stated-preference data, Wang (2001) shows a further extension of store opening hours on Sundays will result in a shift of shopping activity to Sundays. Yet, an increase in shopping intensity or duration is not to be expected.

\subsection{Activity/travel context}

A second set of variables influencing shopping duration relates to the activity/travel episodes surrounding the shopping activity. After all, choices about activity participation, activity duration, destination choice, and so forth are highly interdependent and affect the opportunities available for following activities. For example, a number of studies have shown that activity duration and travel time are positively correlated (Bhat, 2001; Dijst and Vidakovic, 2000; Schwanen and Dijst, 2002). Assuming a sequential activity-scheduling process, it is anticipated that the greater the effort individ- 
uals have to make in traveling to their present location, the longer the time spent shopping will be. Bhat's (1996) findings that shopping activities on the way home from work are shorter for individuals driving alone than for those who rideshare, or use mass transit are also relevant in this respect.

Further, the time people have already been engaged in shopping may influence the duration of a shopping episode. Tonn (1984) showed that a person who has already allocated some time to purchasing goods earlier in the day may be less prepared to conduct further long shopping activities, because at least part of the need for shopping has already been satisfied.

\subsection{Monetary budget constraints}

Time allocation may be subject not only to temporal, but also to monetary constraints (Kraan, 1996). A worker's income or that of his/her household is an obvious indicator of monetary constraints. Niemeier and Morita (1996), and Bhat (2001) for the return-home commute, show that visits to shops tend to last longer when the household income is higher. Presumably, the greater spending capacity of higher-income households facilitates more intensive participation in shopping, particularly for the purchase of consumer goods.

\subsection{The spatial context of the shopping episode}

In addition to the temporal and monetary constraints and the activity/travel context, characteristics of the built environment surrounding the home or work location or features of the location where the shopping is conducted may affect the duration of shopping episodes. Larger settlements and those with higher densities - in short: the more urbanized settings - are likely to have more shops and a more differentiated product range available within a given distance. This enhanced availability of shopping opportunities may affect shopping behavior, including time allocation.

Although an association between shopping duration and spatial context is intuitively agreeable, previous research has paid little attention to the spatial variation in the duration of shopping activities. ${ }^{1}$ Most studies that have analyzed the impact of locational characteristics on shopping duration have limited themselves to the total daily time allocated to shopping. In other words, daily aggregations of shopping time are investigated rather

\footnotetext{
${ }^{1}$ In retailing studies, considerable attention has been given to the influence of 'atmospherics' (intentional control and structuring of environmental cues) on shopping time. An overview of these studies is presented in Turley and Milliman (2000). Because most atmospherics relate to the interior of shops, these studies are left out of consideration.
}

than individual shopping episodes. For example, Levinson (1999) finds for the USA that, as residential density increases and metropolitan regions become larger, people spend less time on out-of-home shopping. One study investigating shopping episodes that does incorporate locational characteristics as explanatory variables is Bhat's (2001) investigation of activities during the return-home commute. He shows that when workers live in an urban neighborhood, they spend less time on a shopping episode, whereas workers allocate more time to a shopping episode when their workplace is located in an urban environment. No explanation for this result is provided.

Two apparently incompatible hypotheses may be formulated about the effect of the degree of urbanization on shopping episode duration. A spatial flexibility hypothesis states that if many shopping opportunities are readily accessible from the home or workplace, little travel is needed to visit a shopping facility. Assuming a fixed need for shopping across individuals, an individual in a more urbanized environment can travel to a shop more frequently at no greater total cost than a person living in a less urbanized environment. Crane (1996) presents a similar argument concerning the trip-inducing effects of neo-traditional urban neighborhoods; Handy (1996) provides empirical support for additional trip making for shopping purposes in high-density, mixeduse neighborhoods. If the number of shopping trips and activity episodes is higher in more urbanized environments, the time spent per episode may be less. One reason for this is that the need to buy as many goods as possible in a single shopping event is lower. In short, the spatial flexibility hypothesis predicts on average shorter shopping episodes as the degree of urbanization increases.

In contrast, the larger number and more varied supply of shopping opportunities may also act as an inducement to more extensive activity participation. If shopping is more interesting, or even exhilarating in a more urbanized environment, people may be less inclined to stop participating once they have decided to go shopping. This idea is consistent with the notion that shopping activities fulfill more purposes than the mere purchase of goods, such as a need for social interaction, or variety seeking (Mokhtarian and Salomon, 2001; Tonn, 1984). Furthermore, high-order consumer goods are usually only available in larger shopping centers in more urbanized environments, so the type of goods purchased varies with the type of environment. The purchase of high-order consumer goods may take more time than buying groceries, partly because people often spend considerable time in browsing and evaluating products. The spatial variety hypothesis therefore predicts that, all else being equal, individuals allocate more time per shopping activity in more urbanized environments than in less urbanized environments. 


\section{Research design}

\subsection{Study approach}

The current paper intends to determine the extent to which the duration of shopping episodes on workdays varies with characteristics of the environment in which they are conducted, temporal constraints, the activity/ travel context of the episode, and monetary budget constraints (Table 1). Because the importance of temporal constraints varies during the day, the analysis is disaggregated by period of workday. Following Damm (1979) and others, five periods are discerned: before home-to-work; home-to-work; during work; workto-home; and post home-arrival period. The analysis is also disaggregated by gender, for two reasons. First, while women have increasingly become engaged in paid labor, they have remained responsible for the majority of household chores and perform most shopping duties (Bhat, 1996; Niemeier and Morita, 1996; Schwanen and Dijst, 2003). They are the ones to experience most time pressure (Breedveld and Van den Broek, 2001). Second, some evidence exists that women seem to enjoy shoppingespecially for consumer goods-more than men do, which is consistent with the "...prevailing stereotypes of shopping as a female activity" (Dholakia, 1999, p. 192).

Table 1

Variable definitions

\begin{tabular}{|c|c|}
\hline Variable name & Description \\
\hline \multicolumn{2}{|l|}{ Temporal constraints } \\
\hline Work duration & Time allocated to out-of-home work activities on the day of inquiry (in min) \\
\hline Employment status & $\begin{array}{l}\text { Total number of hours worked a week: } \\
\bullet<30 \mathrm{~h} \text { per week } \\
\bullet \geqslant 30 \mathrm{~h} \text { per week }\end{array}$ \\
\hline Work duration spouse & Time allocated to out-of-home work activities by the worker's spouse on the day of inquiry (in min) \\
\hline Employment status spouse & $\begin{array}{l}\text { Total number of hours worked a week by the worker's spouse: } \\
\text { - Non-working spouse } \\
\text { - }<30 \mathrm{~h} \text { per week } \\
\text { - } \geqslant 30 \mathrm{~h} \text { per week } \\
\text { - No spouse } \\
\text { - Spouse status unknown }\end{array}$ \\
\hline Commute distance & Self-reported distance between the home and work location (in $\mathrm{km}$ ) \\
\hline Number of trips in journey & $\begin{array}{l}\text { The number of trips in the chain of travel/activity episodes that starts at the home/workplace and ends at the } \\
\text { home/workplace; a proxy for the number of activities to be performed during a time window }\end{array}$ \\
\hline Age of the youngest child & $\begin{array}{l}-0-5 \text { years } \\
\text { - } 6-11 \text { years } \\
\text { - } 12-17 \text { years } \\
\text { - Adult child/no child }\end{array}$ \\
\hline Day of the week & Monday through Sunday; a proxy for store hours \\
\hline \multicolumn{2}{|c|}{ Activity/travel context surrounding the shopping episode } \\
\hline Distance to access activity & Self-reported distance between the previous and the current activity episode (in $\mathrm{km}$ ) \\
\hline Transportation mode & $\begin{array}{l}\text { Main travel mode on the trip to the current activity episode: } \\
\text { - Car driver } \\
\text { - Car passenger } \\
\text { - Bicycle } \\
\text { - Walking } \\
\text { - Other modes (including public transportation) }\end{array}$ \\
\hline Time previously spent shopping & The total time allocated to shopping until the start of the present activity episode (in min) \\
\hline $\begin{array}{l}\text { Monetary budget constraints } \\
\text { Household income }\end{array}$ & $\begin{array}{l}\text { Total net annual income of the worker's household: } \\
\text { - < Euro } 12,250 \\
\text { - Euro } 12,250-19,049 \\
\text { - Euro } 19,050-26,299 \\
\text { - } \geqslant \text { Euro } 26,300\end{array}$ \\
\hline \multicolumn{2}{|c|}{ Spatial environment of the shopping episode } \\
\hline Spatial location & $\begin{array}{l}\text { - Randstad Holland, three large cities } \\
\text { - Randstad Holland, medium-sized cities } \\
\text { - Randstad Holland, suburbs } \\
\text { - Randstad Holland, growth centers } \\
\text { - Rest of The Netherlands, more urbanized } \\
\text { - Rest of The Netherlands, less urbanized }\end{array}$ \\
\hline
\end{tabular}




\subsection{Data and definitions}

Data from the 1998 Netherlands National Travel Survey (NTS) were used. Started in 1978, this survey is a continuous inquiry into the travel behavior of households. Every year, some 70,000 households participate in the survey, yielding data on the travel behavior of about 130,000 individuals over the age of 4 . In addition to information on personal and household attributes, respondents are asked to complete a trip diary for an entire day, one section of which requires the reporting of the characteristics of all trips (Statistics Netherlands, 1999).

The duration of stops in the activity patterns was calculated on the basis of the information reported by the respondents. Because no information was available about on-site activity participation, it was assumed that activity-episode duration was equal to stop duration. Another limitation of the data is that types of shopping activities (groceries, consumer goods, and so forth) could not be differentiated. It was nevertheless felt that the data yielded potentially useful information, because the large sample size permitted the estimation of segmented models. In addition, the data covers all spatial environments and population categories to be found in The Netherlands.

From the approximately 130,000 daily activity patterns available within the 1998 NTS, the following were selected: days on which at least one commute trip was made; days for which complete information about all trips was available; patterns from male and female heads of households. In total, the data contain 23,831 complete activity patterns of working household heads and their partners undertaking at least one commute trip. These commuting days are further referred to as workdays. On 6017 of these workdays $(25.2 \%)$, one or more shopping activities were conducted. Thus, in the empirical analysis, data were used from 6017 working individuals who collectively pursued 7542 shopping activities on the day on which they kept a travel diary. For these individuals the NTS contains information about a range of personal and household factors which have been used to create a set of explanatory variables for the empirical analysis (Table 1).

In addition to these personal and household characteristics, a large number of other explanatory variables have been developed. Store hours vary considerably in The Netherlands. Since 1996, the national government has allowed shops to be open between 6 AM and 10 PM on weekdays and Saturdays. At the local level, however, a large variation in opening times can be observed, partly as a result of local government regulation. In 1998, most shops used to be open between 9 AM and 6 PM on weekdays and Saturdays; on one evening per week - typically on Thursday or Friday-shops were allowed to remain open until 9 PM. This was usually referred to as the shopping evening in The Netherlands. Supermarkets tended to have extended opening hours (from 8 AM to $8 \mathrm{PM}$ ). On Sundays, shops were normally closed with the exception of a few Sundays per year (in December, for example). Detailed information on store opening hours was not available for all local authorities, so in this research the day of the week has been used as a crude proxy indicator of opening hours.

The spatial distribution of shops is characterized by a strong hierarchical structure. Traditionally, retail facilities have been spatially distributed according to the principles of central-place theory: the higher-order shops were almost exclusively located in the larger city centers, whereas lower-order shops were clustered in small shopping centers in residential neighborhoods and smaller settlements (Borchert, 1988). This spatial retail policy seems to have inhibited the large-scale decentralization of shops to car-oriented, suburban locations (Evers, 2002). Over the past few years, however, the suburbanization of shops to locations with good access to the main road infrastructure has become easier. Nevertheless, the traditional situation prevailed to a large extent in 1998.

Ideally, neighborhoods where shopping activities are executed should be classified in accordance with the spatial distribution of shops. For privacy reasons, however, data at the neighborhood level are not available in the NTS. As a consequence, a classification of Dutch local authorities into six categories was used (Fig. 1),

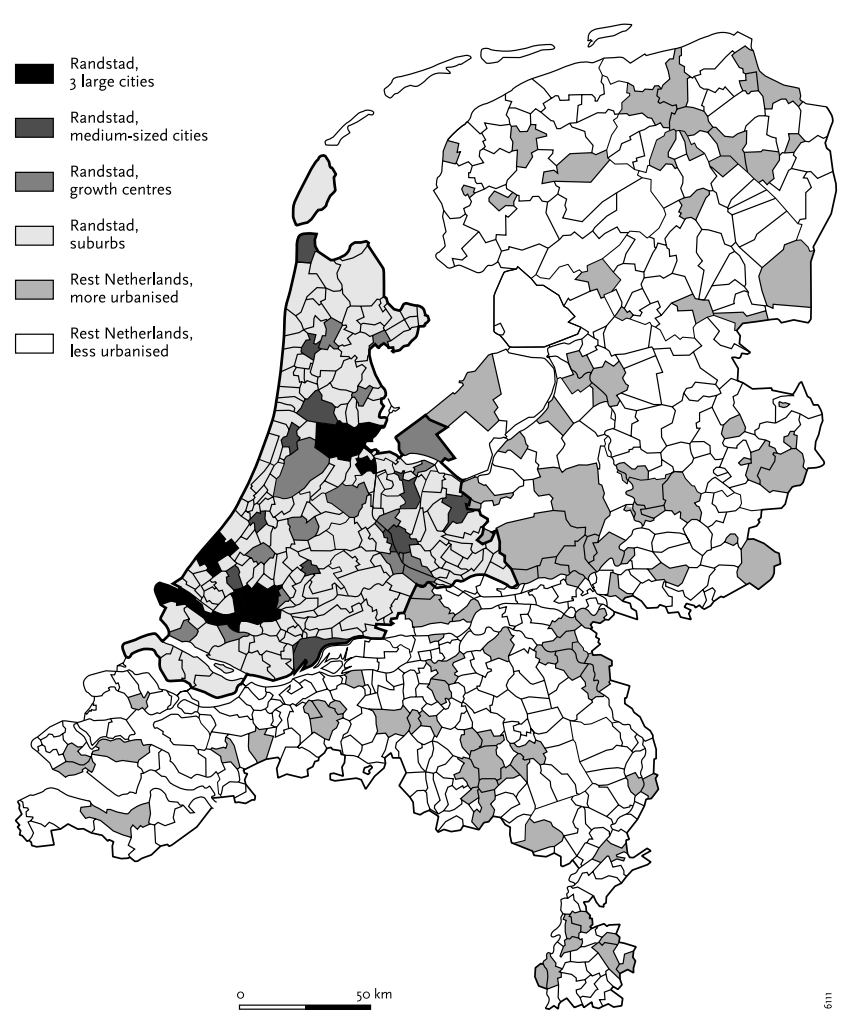

Fig. 1. Spatial environments in The Netherlands. 
which combines the interdependent urban form characteristics of city size, residential density, and land-use mixing. Two criteria lie at the heart of the categorization: the location of a local authority within or outside the Randstad Holland; its urbanization level. Randstad Holland is the heavily urbanized Western part of The Netherlands. Local authorities located here are divided into three large cities (Amsterdam, Rotterdam, The Hague); medium-sized cities (including Utrecht); and suburbs. The numbers of shopping opportunities and product ranges offered vary markedly among these types of local authorities. They are largest in Amsterdam, Rotterdam, and The Hague and smallest in the suburban environments. A fourth category is distinguished within the Randstad Holland, the growth centers or new towns. These communities were expressly planned in the 1970s and 1980s to encompass firms and households relocating from the larger cities. They evolved into dormitory towns whose residents show travel patterns that clearly deviate from those of people residing elsewhere (Schwanen et al., 2002). Outside the Randstad Holland, locations are dichotomized into more urbanized and less urbanized. Clearly, the supply of shopping opportunities is larger and more varied in the former. Moreover, the number of shopping opportunities in the latter type of environment has been reduced over the past decades; many local shops were closed as a result of increased competition, profit maximization by retailers, and higher car availability and use among consumers (Borchert, 1988).

\subsection{Cox regression models}

Hazard-based models are most appropriate for the investigation of the effects of spatial and other factors on non-negative variables such as shopping duration. This class of models focuses on the hazard rate, or the probability that an event or activity is terminated given that it has lasted until some specified time $t$ (Hensher and Mannering, 1994). A higher hazard rate implies a shorter expected activity duration. For the analysis of the effects of independent variables (covariates), the proportional-hazard formulation is often used:

$h(t \mid \mathbf{Z})=h_{0}(t) \exp (\beta \mathbf{Z})$

where $\mathbf{Z}$ is a vector of covariates, $\beta$ is a vector of parameters to be estimated, and $h_{0}(t)$ is the baseline hazard function. It is assumed that the hazards for two individuals with different covariates are proportional. Thus, the effect of external covariates is to shift the entire hazard function up or down; the functional profile remains the same for every individual. Cox (1972) developed a semi-parametric, partial-likelihood approach for estimating hazard-based models. The advantage of this approach is that it avoids the pitfall of inconsistent baseline-hazard estimates resulting from the specification of an incorrect distribution form (Mannering et al., 1994). The Cox approach has been used quite frequently in activity-based travel-demand analysis. Some recent examples include Yee and Niemeier (2000) and Timmermans et al. (2002).

To correct for violations of the proportional hazard assumption, time-varying covariates are included in the models. These covariates consist of interactions between time-constant variables and a duration variable $t$. The decision whether or not to include time-varying covariates was made after visual inspection of the estimated partial residuals (Schoenfeld, 1982) and estimation of models with interaction effects between covariates and duration (Yamaguchi, 1991). The final definition of the interactions was chosen so as to maximize the statistical model improvement after their inclusion.

\section{Shopping activities by gender and period of day}

This section presents some descriptive analyses of the duration of shopping episodes on workdays as an introduction to the more formal modeling of shopping duration. Consideration is first given to the allocation of shopping activities to different parts of the workday, however, because understanding of the duration of shopping episodes may thereby be enhanced.

As expected, females are more likely to pursue shopping activities on workdays than men, but the overall gender difference is not particularly large: of all the shopping activities on workdays, $58 \%$ are conducted by women versus $42 \%$ by men. The magnitude of this gender difference varies, however, with the period of the day. In particular, females conduct more shopping activities than men do in the period before the hometo-work commute and during the return-home commute. Males, on the other hand, undertake most of their shopping after they have returned home from work (Table 2). The type of spatial location is only weakly related to shopping propensity. The average number of shopping episodes per worker who engaged in shopping was calculated for each of the six spatial locations. Kruskall-Wallis tests indicate that there were no statistically significant differences for men, although the total number of shopping activities per female purchasing goods did vary statistically significantly with the spatial environment (at the 10\% level). The only clear difference is, however, that the average for the growth centers is lower than elsewhere, indicating that the working women who shop there are the least likely to engage in more than one shopping episode. In short, no strong empirical support has been found for the contention that residing in a more urbanized environment induces more frequent shopping participation on workdays for either male or female heads of households. 
Table 2

Shopping episodes by gender and period of workday

\begin{tabular}{|c|c|c|c|c|c|c|}
\hline & \multicolumn{2}{|c|}{ Male head of household } & \multicolumn{2}{|c|}{ Female head of household } & \multicolumn{2}{|l|}{ Total } \\
\hline & $N$ & $\%$ of Total & $N$ & $\%$ of Total & $N$ & $\%$ of Total \\
\hline Before home-to-work period & 249 & 7.8 & 563 & 13.0 & 812 & 10.7 \\
\hline Home-to-work period & 126 & 3.9 & 159 & 3.7 & 285 & 3.8 \\
\hline During-work period & 342 & 10.4 & 416 & 9.6 & 758 & 10.1 \\
\hline Work-to-home period & 810 & 25.3 & 1350 & 31.1 & 2160 & 28.6 \\
\hline Post home-arrival period & 1682 & 52.6 & 1855 & 42.7 & 3537 & 46.9 \\
\hline Total & 3199 & 100.0 & 4343 & 100.0 & 7542 & 100.0 \\
\hline
\end{tabular}

A note of caution needs to be made, however, because it is still possible that the frequency of shopping participation per week, or shopping propensity on non-workdays vary with the degree of urbanization. Unfortunately, differences on a weekly basis could not be assessed, because the NTS only provides single-day trip data.

With regard to shopping duration, the analysis corroborates the hypothesis that women allocate more time to separate shopping episodes (Table 3). The average duration also varies with the period of the workday. The mean is lowest in the during-work period, which may be related to the fact that many shopping activities in this period consist of workers leaving their workplace to buy lunch. The averages for the two commute periods are highest, while those for the before home-to-work and post home-arrival periods have intermediate values. The higher averages for the commute periods result from a small number of shopping activities during the commute periods having a very long duration. In the majority of cases, shopping episodes nested in the commute last less time than visits to shops following home arrival.

An ANOVA indicated that the spatial environment in which the shopping is conducted affects its duration after account is taken of gender and time of day. In fact, the test shows that the three-way interaction between gender, time of day, and spatial location is significant (Table 4). In other words, the effect of the spatial environment varies for men and women between various parts of the day. The estimation of separate Cox regression models can therefore be justified not only on theoretical grounds, but also on the basis of these empirical results.
Table 4

ANOVA of the duration of shopping episodes (in min) on workdays

\begin{tabular}{lrl}
\hline & $F$-statistic & $p$ \\
\hline Main effects & & \\
Intercept & 1307.5 & 0.000 \\
Gender & 21.9 & 0.000 \\
Period of workday & 26.4 & 0.000 \\
Spatial location & 7.4 & 0.000 \\
Interaction effects & & \\
Gender $*$ period of workday & 2.1 & 0.083 \\
Gender $*$ spatial location & 0.8 & 0.609 \\
Period of workday $*$ spatial location & 1.6 & 0.054 \\
Gender $*$ period of workday $*$ spatial & 1.8 & 0.018 \\
$\quad$ location & & \\
\hline
\end{tabular}

\section{Determinants of the duration of shopping activities}

This part of the paper describes the Cox regression analyses of the duration of shopping episodes, disaggregated by gender and time of day. Table 5 contains all models for working female heads of households; Table 6 those for working men. Only variables that are statistically significant, or approach significance (in all cases $p<0.20$ ), are included in the final model specifications. The results should be interpreted as follows: a positive coefficient increases the hazard and thus decreases the expected or average activity duration, whereas a negative coefficient is indicative of a longer duration.

\subsection{Temporal constraints}

Six out of 10 models support the hypothesis that the time allocated to work negatively affects the duration of

Table 3

Average duration of shopping episodes (in min) by gender and period of workday

\begin{tabular}{|c|c|c|c|c|c|c|}
\hline & \multicolumn{2}{|c|}{ Male head of household } & \multicolumn{2}{|c|}{ Female head of household } & \multicolumn{2}{|l|}{ Total } \\
\hline & Mean & S.D. & Mean & S.D. & Mean & S.D. \\
\hline Before home-to-work period & 25.4 & 29.6 & 34.6 & 34.5 & 31.8 & 33.4 \\
\hline Home-to-work period & 33.4 & 66.0 & 46.0 & 66.6 & 40.4 & 66.5 \\
\hline During-work period & 16.2 & 21.4 & 20.0 & 21.2 & 18.3 & 21.4 \\
\hline Work-to-home period & 35.0 & 61.2 & 38.9 & 60.5 & 37.5 & 60.8 \\
\hline Post home-arrival period & 29.2 & 28.9 & 34.5 & 36.8 & 32.0 & 33.3 \\
\hline Total & 29.2 & 41.2 & 34.9 & 45.9 & 32.5 & 44.0 \\
\hline
\end{tabular}


Table 5

Cox regression models of the duration of shopping episodes for working female heads of households by period of workday

\begin{tabular}{|c|c|c|c|c|c|c|c|c|c|c|c|c|c|c|c|}
\hline & \multicolumn{3}{|c|}{$\begin{array}{l}\text { Before home-to-work } \\
\text { period }\end{array}$} & \multicolumn{3}{|c|}{ Home-to-work period } & \multicolumn{3}{|c|}{ During-work period } & \multicolumn{3}{|c|}{$\begin{array}{l}\text { From work-to-home } \\
\text { period }\end{array}$} & \multicolumn{3}{|c|}{ Post home-arrival period } \\
\hline & $\beta$ & SE & $p$ & $\beta$ & $\mathrm{SE}$ & $p$ & $\beta$ & $\mathrm{SE}$ & $p$ & $\beta$ & $\mathrm{SE}$ & $p$ & $\beta$ & $\mathrm{SE}$ & $p$ \\
\hline \multicolumn{16}{|l|}{ Temporal constraints } \\
\hline $\begin{array}{l}\text { Work duration on day of } \\
\text { inquiry }\end{array}$ & & & & & & & 0.001 & 0.000 & 0.032 & & & & $5.1 \mathrm{E}-04$ & $1.7 \mathrm{E}-04$ & 0.003 \\
\hline $\begin{array}{l}t<60 * \mathrm{LN} \text { (work duration on } \\
\text { day of inquiry) }\end{array}$ & & & & & & & & & & 0.270 & 0.061 & 0.000 & & & \\
\hline $\begin{array}{l}t<30 * \text { works } \geqslant 30 \mathrm{~h} \text { per } \\
\quad \text { week }\end{array}$ & & & & 0.747 & 0.226 & 0.001 & & & & & & & & & \\
\hline $\begin{array}{l}\text { Work duration partner on day } \\
\text { of inquiry }\end{array}$ & & & & & & & 0.002 & 0.001 & 0.018 & & & & & & \\
\hline $\begin{array}{l}\text { Partner works } \geqslant 30 \mathrm{~h} \text { per } \\
\text { week }\end{array}$ & & & & -0.243 & 0.181 & 0.180 & -0.236 & 0.105 & 0.025 & & & & & & \\
\hline $\begin{array}{l}t<30 * \text { partner works }>12 \mathrm{~h} \\
\text { per week }\end{array}$ & & & & & & & & & & & & & 0.241 & 0.072 & 0.001 \\
\hline LN(commute distance $)$ & -0.067 & 0.035 & 0.058 & & & & & & & & & & & & \\
\hline Number of trips in the journey & -0.258 & 0.120 & 0.031 & & & & 0.262 & 0.060 & 0.000 & & & & 0.316 & 0.041 & 0.000 \\
\hline$t *$ number of trips & & & & & & & & & & & & & -0.006 & 0.001 & 0.000 \\
\hline$t<20 \min *$ number of trips & & & & & & & & & & 0.765 & 0.128 & 0.000 & & & \\
\hline$t<45 \min *$ number of trips & 0.476 & 0.129 & 0.000 & 0.229 & 0.108 & 0.034 & & & & & & & & & \\
\hline Youngest child aged 12-17 & -0.367 & 0.129 & 0.005 & 0.443 & 0.280 & 0.113 & & & & & & & & & \\
\hline Monday & 0.443 & 0.133 & 0.001 & & & & & & & & & & & & \\
\hline Thursday & 0.219 & 0.115 & 0.058 & & & & & & & -0.119 & 0.070 & 0.090 & -0.192 & 0.060 & 0.001 \\
\hline Friday & 0.289 & 0.116 & 0.130 & & & & -0.357 & 0.148 & 0.016 & & & & & & \\
\hline$t<30 *$ Friday & & & & & & & & & & -0.409 & 0.091 & 0.000 & -0.401 & 0.074 & 0.000 \\
\hline Sunday & 1.389 & 0.457 & 0.002 & & & & & & & & & & & & \\
\hline \multicolumn{16}{|l|}{ Activity/travel context } \\
\hline $\begin{array}{l}\text { Distance to access the activity } \\
\text { episode }\end{array}$ & & & & & & & -0.107 & 0.024 & 0.000 & & & & & & \\
\hline $\mathrm{LN}($ distance $)$ & -0.309 & 0.041 & 0.000 & & & & & & & & & & -0.183 & 0.034 & 0.000 \\
\hline$t<30 \min * \mathrm{LN}($ distance $)$ & & & & & & & & & & & & & -0.176 & 0.413 & 0.000 \\
\hline Car passenger & -0.423 & 0.168 & 0.012 & & & & & & & -0.235 & 0.120 & 0.050 & & & \\
\hline Bicycle & & & & & & & & & & 0.367 & 0.061 & 0.000 & 0.165 & 0.062 & 0.007 \\
\hline Walking & & & & & & & & & & & & & 0.138 & 0.078 & 0.079 \\
\hline Other modes & & & & & & & 0.296 & 0.109 & 0.007 & & & & & & \\
\hline \multicolumn{16}{|l|}{ Monetary constraints } \\
\hline $\begin{array}{l}\text { Household income Euro } \\
19,050-26,299\end{array}$ & & & & & & & & & & 0.211 & 0.092 & 0.022 & & & \\
\hline \multicolumn{16}{|l|}{ Spatial environment } \\
\hline $\begin{array}{l}\text { Randstad Holland, three large } \\
\text { cities }\end{array}$ & -0.380 & 0.186 & 0.041 & & & & & & & & & & & & \\
\hline $\begin{array}{l}\text { Randstad Holland, medium } \\
\text { cities }\end{array}$ & & & & & & & & & & -0.172 & 0.093 & 0.063 & & & \\
\hline Randstad Holland, suburb & & & & & & & 0.222 & 0.139 & 0.110 & 0.295 & 0.093 & 0.002 & & & \\
\hline
\end{tabular}


shopping episodes. As the time spent working on the day of inquiry increases, men's shopping episodes tend to be shorter during the two commute periods and the post home-arrival period. For women, the effect is statistically significant in the during-work and post homearrival periods. In addition, for shopping activities conducted by females on the return-home commute, the probability of terminating the activity is larger for $t<60$ min, implying an over-representation of shopping activities of a limited duration during this part of the workday. Furthermore, employment status is included as an explanatory variable in two additional models. Shopping episodes tend to be shorter during the before home-to-work period for men working more than $30 \mathrm{~h}$ a week, while many activities conducted by women during the commute to work tend to take less than half an hour.

Consistent with previous research (Bhat, 1996), the effects of work duration are not limited to the shopping participation of workers themselves. The time devoted to paid labor on a daily or weekly basis also has implications for the spouse's shopping behavior on workdays. The more their female partners work, the longer males' shopping episodes in the during-work period tend to last, while those before and during the commute to work take more time when the spouse is employed for over $30 \mathrm{~h}$ or for $12-29 \mathrm{~h}$ per week respectively. Similarly, women's activities in the home-to-work and duringwork periods last longer when the male head of household works more than $30 \mathrm{~h}$ a week. These results suggest that, when both spouses are employed, the responsibilities for household maintenance are shared between the heads of household and allocated to individuals on the basis of the available time budget.

In some instances, however, the duration of shopping activities decreases with the time the spouse allocates to paid labor. In particular, the more time the partner devotes to work on the day of inquiry, the shorter women's shopping episodes during work become, while those in the post home-arrival period also take less time when the partner works over $30 \mathrm{~h}$ a week. The same effect can be noticed for males' shopping activities on the return-home commute. It appears that, in two-worker households, the time allocated to shopping on workdays is sometimes expressly limited so that more time becomes available for recreation or social activities.

While work duration is an important determinant of shopping duration, the direct impact of commute distance is much more limited. Commute distance is only included in the model for females for the before hometo-work period, showing that episode duration increases with commute distance (Table 5). The effect of having children is also limited. Only for shopping activities before work is the age of the youngest child important. For women whose youngest child is aged 12-17, episodes conducted in the before home-to-work period are 
Table 6

Cox regression models for the duration of shopping episodes for working male heads of households by period of workday

\begin{tabular}{|c|c|c|c|c|c|c|c|c|c|c|c|c|c|c|c|}
\hline & \multicolumn{3}{|c|}{$\begin{array}{l}\text { Before home-to-work } \\
\text { period }\end{array}$} & \multicolumn{3}{|c|}{ Home-to-work period } & \multicolumn{3}{|c|}{ During-work period } & \multicolumn{3}{|c|}{$\begin{array}{l}\text { From work-to-home } \\
\text { period }\end{array}$} & \multicolumn{3}{|c|}{ Post home-arrival period } \\
\hline & $\beta$ & SE & $p$ & $\beta$ & SE & $p$ & $\beta$ & SE & $p$ & $\beta$ & $\mathrm{SE}$ & $p$ & $\beta$ & SE & $p$ \\
\hline \multicolumn{16}{|l|}{ Temporal constraints } \\
\hline $\begin{array}{l}\text { Work duration on day of } \\
\text { inquiry }\end{array}$ & & & & 0.002 & 0.001 & 0.001 & & & & 0.001 & 0.000 & 0.004 & $4.1 \mathrm{E}-04$ & 0.000 & 0.013 \\
\hline Works $\geqslant 30 \mathrm{~h}$ per week & 0.458 & 0.196 & 0.019 & & & & & & & & & & & & \\
\hline $\begin{array}{l}\text { Work duration partner on day } \\
\text { of inquiry }\end{array}$ & & & & & & & -0.003 & 0.002 & 0.086 & & & & & & \\
\hline $\begin{array}{l}\text { Partner works } \geqslant 30 \mathrm{~h} \text { per } \\
\text { week }\end{array}$ & -0.295 & 0.177 & 0.096 & & & & & & & 0.121 & 0.086 & 0.163 & & & \\
\hline $\begin{array}{l}\text { Partner works } 12-29 \mathrm{~h} \text { per } \\
\text { week }\end{array}$ & & & & -0.474 & 0.233 & 0.042 & & & & & & & & & \\
\hline $\begin{array}{l}\text { Youngest child aged 12-17 } \\
\text { years }\end{array}$ & 0.420 & 0.282 & 0.136 & & & & & & & & & & & & \\
\hline Number of trips in the journey & 0.159 & 0.097 & 0.102 & 0.180 & 0.110 & 0.102 & & & & 0.120 & 0.036 & 0.001 & 0.289 & 0.047 & 0.000 \\
\hline$t *$ number of trips & & & & & & & & & & & & & -0.004 & 0.002 & 0.005 \\
\hline Wednesday & & & & -0.366 & 0.244 & 0.134 & & & & & & & & & \\
\hline Thursday & & & & & & & & & & -0.224 & 0.096 & 0.020 & -0.313 & 0.065 & 0.000 \\
\hline Friday & & & & & & & -0.235 & 0.141 & 0.096 & & & & & & \\
\hline$t<30 *$ Friday & & & & & & & & & & & & & & & \\
\hline$t<40 *$ Friday & & & & & & & & & & -0.286 & 0.098 & 0.004 & -0.453 & 0.065 & 0.000 \\
\hline \multicolumn{16}{|l|}{ Activity/travel context } \\
\hline $\begin{array}{l}\text { Distance to access the activity } \\
\text { episode }\end{array}$ & & & & & & & -0.024 & 0.013 & 0.058 & & & & -0.214 & 0.038 & 0.000 \\
\hline$t<30 \min * \mathrm{LN}($ distance $)$ & & & & & & & & & & & & & -0.166 & 0.046 & 0.000 \\
\hline $\begin{array}{l}\text { Time previously spent shop- } \\
\text { ping }\end{array}$ & & & & & & & & & & & & & $1.8 \mathrm{E}-04$ & 0.000 & 0.013 \\
\hline Car passenger & & & & & & & & & & & & & -0.198 & 0.107 & 0.064 \\
\hline Bicycle & & & & & & & & & & 0.334 & 0.094 & 0.000 & & & \\
\hline Other modes & & & & & & & & & & & & & -0.498 & 0.262 & 0.057 \\
\hline \multicolumn{16}{|l|}{ Monetary constraints } \\
\hline $\begin{array}{l}\text { Household Income Euro } \\
12,250-19,049\end{array}$ & & & & & & & & & & 0.199 & 0.112 & 0.075 & & & \\
\hline \multicolumn{16}{|l|}{ Spatial environment } \\
\hline $\begin{array}{l}\text { Randstad Holland, three large } \\
\text { cities }\end{array}$ & & & & -0.905 & 0.342 & 0.008 & & & & -0.249 & 0.124 & 0.047 & & & \\
\hline $\begin{array}{l}\text { Randstad Holland, medium } \\
\text { cities }\end{array}$ & & & & -0.793 & 0.353 & 0.025 & 0.272 & 0.159 & 0.086 & -0.178 & 0.127 & 0.159 & & & \\
\hline $\begin{array}{l}\text { Randstad Holland, growth } \\
\text { center }\end{array}$ & & & & & & & & & & -0.156 & 0.168 & 0.016 & -0.245 & 0.102 & 0.017 \\
\hline $\begin{array}{l}75<t<120 * \text { Randstad } \\
\text { Holland, growth center }\end{array}$ & & & & & & & & & & & & & 0.688 & 0.412 & 0.095 \\
\hline
\end{tabular}




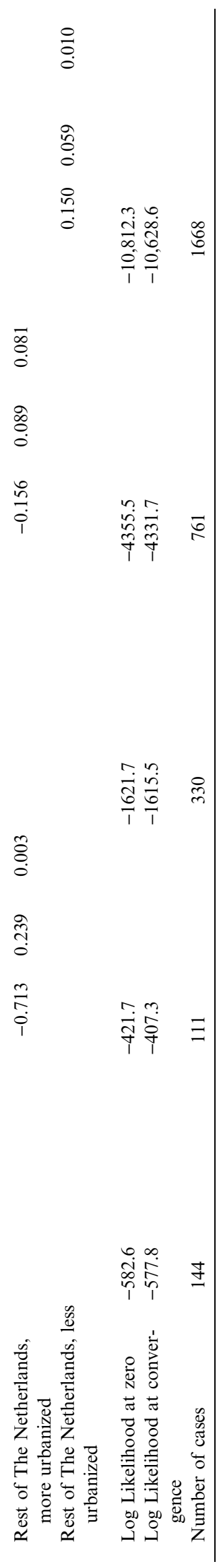

longer, while those in the home-to-work period are shorter than episodes for other women. Shopping episodes before traveling to work undertaken by men in households where the youngest child is aged $12-17$ years also take less time.

Coupling constraints also result from the number of activities a worker has to perform during a time window. This factor is included in one way or another in all the models but one, the exception being that for men's during-work period. As expected, shopping activities consume less time, as the number of trips or activity episodes rises. However, the effect of the number of trips often tapers off with time and in three cases - the before home-to-work period for women and the post home-arrival period for males and females-the effect eventually reverses. This result seems to indicate that long-lasting shopping activities are only combined with other activities in a single journey when very long periods of time are available for out-of-home activities.

Store hours appear to be an important determinant of shopping episode duration, especially for working women. As explained above, the day of the week is used as a proxy measure for store hours. Females' shopping episodes in the before home-to-work period are shorter if they are pursued on Sundays, reflecting that when shops are open they are usually closed until noon. The same relationship, albeit weaker, can be noticed for females' shopping activities before they travel to work on Mondays. On Thursdays and Fridays, women's shopping episodes before traveling to work also tend to be shorter and episodes during the return-home and post home-arrival periods longer. Apparently, women use the temporally more extended supply of retail facilities on these days (the shopping evening) to shift long shopping activities to the after-work periods. Working men also spend more time per shopping episode after work on Thursdays and Fridays.

\subsection{Activity/travel context and monetary constraints}

The immediate activity/travel context of the shopping episode has a clear impact on shopping duration. Shopping activities tend to last longer when a worker has traveled a greater distance to reach the shopping facility. However, the effect of distance tapers off with activity duration in the post home-arrival period for both men and women. Thus, the utility received from the participation in the shopping activity compensates the disutility of traveling. The diminishing effect of travel distance indicates that this compensation is particularly pertinent during the first $30 \mathrm{~min}$ or so of the shopping activity. The transportation mode used to reach the facility is also related to activity duration. If workers travel on foot or by bicycle, they allocate less time to the activity; if however they travel as a car passenger or by public transportation, they spend more 
time per shopping episode. In general, the effects are consistent with the concept of the travel-time ratio; that is to say, travel time and activity duration are positively correlated (Dijst and Vidakovic, 2000; Schwanen and Dijst, 2002).

In contrast, the amount of time previously spent shopping and household income appear to be relatively unimportant determinants of shopping duration. With regard to previous shopping participation, a statistically significant effect could only be detected for men during the post home-arrival period, revealing that the current episode takes less time, as men's previous participation is larger. In other words, men's need for shopping becomes increasingly saturated on workdays. In addition, income dummy variables are included in the models twice - for men and for women during the return-home commute. Both show that workers from medium-income households engage in relatively short shopping episodes when traveling from work to home. The fact that only limited effects are found of monetary budget constraints and previous shopping participation does not necessarily mean that their real impact is small. It may well be the case that both factors have been poorly operationalized. $^{2}$

\subsection{The spatial environment of the shopping episode}

The environment in which shopping activities are conducted affects their duration. In general terms, shopping episodes on workdays tend to take more time as the degree of urbanization increases.

For females, the duration of shopping episodes is positively correlated with the degree of urbanization both within and outside the Randstad Holland during the before home-to-work and the during-work period. A similar correlation can be found for women visiting retail locations outside the Randstad Holland during the return-home and the post home-arrival parts of the workday. For women visiting shops located in the western part of The Netherlands while commuting, the results are slightly different. Females' shopping episodes during the return-home period tend to last longest when the shopping is undertaken in the medium-sized cities, followed by the three large cities and the new towns. For shopping undertaken in the suburbs during the returnhome commute the hazard rate is first lower and then higher, indicating that the variation in shopping dura-

\footnotetext{
${ }^{2}$ The impact of previous activity engagement stretches across multiple days (Kasturirangan et al., 2002). Because the 1998 NTS only provides single-day data, the influence of activity engagement on previous days could not be included in the analysis. The household income variable in the 1998 NTS primarily differentiates between households with low incomes and those with lower-medium incomes; all households with a medium-high or high income are grouped together in a single income bracket (Schwanen et al., 2002).
}

tion is smaller than in other environments. The only difference for the home-to-work period is that shopping episodes in the new towns tend to last for a shorter time than elsewhere.

For working men, the association between degree of urbanization and shopping duration is strongest for the two commute periods. As the degree of urbanization is higher, shopping episodes tend to last longer. During the post home-arrival period, shopping episodes in the least urbanized areas outside the Randstad Holland tend to be shorter, while episodes lasting between 75 and 120 min are over-represented in the growth centers within the Randstad Holland. The impact of the spatial environment is very limited or absent in the before hometo-work and during-work periods. Table 6 indicates that, for the latter part of the day, men's shopping episodes tend to be shorter if they are conducted in the medium-sized cities of the Randstad Holland. This finding may result from men working in these cities being more likely than their counterparts in other environments to buy lunch at activity locations outside the office.

In short, the impact of the spatial environment is complicated and differs with the time of day for both men and women. However, the estimation, together with the results in Section 5, provides more empirical support for the spatial variety hypothesis than for the spatial flexibility hypothesis. Instead of enabling more frequent but shorter shopping activities, an environment with a larger and more varied supply of shopping opportunities leads to longer shopping episodes for working male and female heads of households. This positive association seems to reflect on the one hand that in more urbanized environments a larger proportion of episodes consists of shopping for consumer goods; shopping for these generally consumes more time. On the other, the presence of a large and varied supply including both high and low-quality shops may provide people with more mental stimuli (Tonn, 1984), and induce them to allocate more time to shopping than initially planned.

One might argue that the longer shopping duration in more urbanized environments is an artifact of the inclusion of variables that measure the travel effort required to reach the shopping facility, such as the distance covered and the mode used. However, models have also been estimated which exclude such variables and those showed similar results: that is to say, shopping activities tend to last longer as the degree of urbanization increases.

\section{Discussion}

This paper has described the investigation of the determinants of the duration of men and women's shopping activities during workdays. It concentrates on 
shopping activities rather than shopping travel, because travel demand is for the largest part derived from people's participation in activities that are separated in space and time. It is believed that a focus on activity duration can enhance our understanding of the relationship between travel patterns and their determinants, such as personal and household characteristics and urban form.

Using data from the 1998 Netherlands National Travel Survey, the research confirmed that temporal constraints and the activity/travel behavior surrounding the shopping episode affect its duration. However, the effects of monetary budget constraints, commute distance, the presence and age of children, and the time previously spent shopping on the day are small for both men and women. After time availability has been taken into account, the spatial environment in which the shopping is pursued matters. Although it does not seem to affect the frequency of shopping on workdays, a larger and more varied supply of shopping facilities seems to act as an inducement to more intensive participation per shopping activity. In other words, more time tends to be spent per shopping episode in more urbanized environments. One behavioral interpretation of this result is that a larger and more varied supply of shopping opportunities induces people to allocate more time to shopping.

While the analysis has yielded clear results on some points, other issues evidently merit more attention in future work. Issues that should be considered more extensively are the effects of past activity engagement and store hours on the duration of shopping episodes. In addition, while some clear results for single-day data have been found, the conclusions might be different if information were used about the duration of all shopping episodes during a complete week. Diary data covering a complete week should preferably be used. This would, for instance, enable an investigation of the impact of shopping activities during weekends and other non-workdays on shopping episodes on workdays. Future research should also use more detailed activity categorizations, distinguishing at least between grocery and consumer shopping, as well as geographical indicators at the neighborhood level. Notwithstanding these limitations, the current study has shown that variations in shopping duration also have a spatial component. An explicit consideration of this geographical variation may provide additional understanding of differences in shopping behavior and time use in general.

\section{Acknowledgements}

The research reported here was made possible by The Netherlands National Science Foundation (NWO), grant 425-13-003, to the Urban and Regional research centre Utrecht (URU). Insightful comments from the anonymous reviewers and Martin Dijst are gratefully acknowledged.

\section{References}

Axhausen, K.W., Gärling, T., 1992. Activity-based approaches to travel analysis: conceptual frameworks, models, and research problems. Transport Reviews 12, 323-341.

Bhat, C.R., 1996. A hazard-based duration model of shopping activity with nonparametric baseline specification and nonparametric control for unobserved heterogeneity. Transportation Research B 30, 189-207.

Bhat, C.R., 2001. Modeling the commute activity-travel pattern of workers: formulation and empirical analysis. Transportation Science $35,61-79$.

Borchert, J.G., 1988. Recent development in retailing in The Netherlands. Tijdschrift voor Economische en Sociale Geografie 79, 220225.

Breedveld, K., Van den Broek, A., 2001. Trends in Time: A Sketch of Recent Developments in Time Use and Time Organization (in Dutch). Social and Cultural Planning Office, The Hague.

Cox, D., 1972. Regression models and life tables. Journal of the Royal Statistical Society Series B 34, 187-202.

Crane, R., 1996. Cars and drivers in the new suburbs: linking access to travel in neotraditional planning. Journal of the American Planning Association 62, 51-65.

Damm, D., 1979. Toward a Model of Activity Scheduling Behavior. Ph.D. thesis, Massachusetts Institute of Technology, Cambridge, MA.

Dholakia, R.R., 1999. Going shopping: key determinants of shopping behaviors and motivations. International Journal of Retail and Distribution Management 27, 154-165.

Dijst, M., Vidakovic, V., 2000. Travel time ratio: the key factor in spatial reach. Transportation 27, 179-199.

Evers, D., 2002. The rise (and fall?) of national retail planning. Tijdschrift voor Economische and Sociale Geografie 93, 107-113.

Handy, S., 1996. Understanding the link between urban form and nonwork travel behavior. Journal of Planning Education and Research 15, 183-198.

Hägerstrand, T., 1970. What about people in regional science? Regional Science Association Papers 24, 7-21.

Hensher, D.A., Mannering, F.L., 1994. Hazard-based duration models and their application to transport analysis. Transport Reviews 14, 63-82.

Kasturirangan, K., Pendyala, R.M., Koppelman, F.S., 2002. On the role of history in modeling activity type choice and activity duration for commuters. Transportation Research Record (forthcoming).

Kitamura, R., Kostyniuk, L.P., Uyeno, M.J., 1981. Basic properties of urban time-space paths: empirical tests. Transportation Research Record 794, 8-19.

Kraan, M., 1996. Time to Travel? A Model for the Allocation of Time and Money. Ph.D. thesis, University of Twente, Enschede.

Levinson, D.M., 1999. Space, money, life-stage, and the allocation of time. Transportation 26, 141-171.

Mannering, F., Murakami, E., Kim, S.G., 1994. Temporal stability of travelers' activity choice and home-stay duration: some empirical evidence. Transportation 21, 371-392.

Mokhtarian, P.L., Salomon, I., 2001. How derived is the demand for travel? Some conceptual and measurement considerations. Transportation Research A 35, 695-719.

Niemeier, D.A., Morita, J.A., 1996. Duration of trip-making activities: a survival analysis. Transportation 23, 353-371.

Schoenfeld, D., 1982. Partial residuals for the proportional hazards regression model. Biometrika 69, 239-241. 
Schwanen, T., Dijst, M., 2002. Travel-time ratios for visits to the workplace: the relationship between commuting time and work duration. Transportation Research A 36, 573-592.

Schwanen, T., Dijst, M., 2003. Time windows in workers' activity patterns: an empirical analysis from The Netherlands. Transportation 30, 261-283.

Schwanen, T., Dijst, M., Dieleman, F.M., 2002. A microlevel analysis of residential context and travel time. Environment and Planning A $34,1487-1507$.

Statistics Netherlands, 1999. 1998 National Travel Survey: Documentation For Tape Users (in Dutch). Statistics Netherlands, Voorburg/Heerlen.

Timmermans, H., Van der Waerden, P., Alves, M., Polak, J., Ellis, S., Harvey, A.S., Kurose, S., Zandee, R., 2002. Time allocation in urban and transport settings: an international, inter-urban perspective. Transport Policy 9, 79-93.
Tonn, B.E., 1984. A sociopsychological contribution to the theory of individual time-allocation. Environment and Planning A 16, 201223.

Turley, L.W., Milliman, R.E., 2000. Atmospheric effects on shopping behavior: a review of the experimental evidence. Journal of Business Research 49, 193-211.

Wang, D., 2001. Impact of institutional policies on individual's participation in non-work activities. Journal of Transport Geography $9,61-74$.

WCED (World Commission on Environment and Development), 1987. Our Common Future. Oxford University Press, Oxford.

Yamaguchi, K., 1991. Event History Analysis. Sage Publications, Inc, Newbury Park, CA.

Yee, J.L., Niemeier, D.A., 2000. Analysis of activity duration using the Puget Sound transportation panel. Transportation Research A 34, 607-624. 